\title{
Percepção e ação acerca da segurança alimentar: um estudo de caso com agricultores
}

\section{familiares em Vitorino/PR}

\author{
Perception and action about food security: a case study of family farmers in Vitorino/PR \\ Percepción y acción sobre seguridad alimentaria: un estudio de caso con familiares en Vitorino/PR
}

Recebido: 06/10/2021 | Revisado: 11/10/2021 | Aceito: 16/10/2021 | Publicado: 18/10/2021

Caroline Viganó

ORCID: https://orcid.org/0000-0001-9199-9988

Universidade Tecnológica Federal do Paraná, Brasil E-mail: vigano.carol@gmail.com

Larisse Medeiros Gonçalves

ORCID: https://orcid.org/0000-0002-8546-3244

Universidade Tecnológica Federal do Paraná, Brasil E-mail: larisse@alunos.utfpr.edu.br

Cristiane Maria Tonetto Godoy

ORCID: https://orcid.org/0000-0001-6150-9976

Universidade Tecnológica Federal do Paraná, Brasil E-mail: guriaccr@hotmail.com

Jose Ricardo da Rocha Campos

ORCID: https://orcid.org/0000-0002-5162-3158

Universidade Tecnológica Federal do Paraná, Brasil E-mail: jricardo28@gmail.com

Wilson Itamar Godoy

ORCID: https://orcid.org/0000-0003-0152-6269

Universidade Tecnológica Federal do Paraná, Brasil E-mail: godoyutfpr@gmail.com

Paulo Henrique de Oliveira

ORCID: https://orcid.org/0000-0002-1339-9108

Universidade Tecnológica Federal do Paraná, Brasil E-mail: henrique@utfpr.edu.br

\begin{abstract}
Resumo
A predominância das terras brasileiras ocupadas pelo plantio de commodities apresenta um modelo de produção ameaçador a segurança e a soberania alimentar do país. Desse modo, a prática de produção para autoconsumo surge como uma estratégia na garantia alimentar de famílias rurais. Trata-se de todo tipo de produção realizada dentro da unidade familiar, na qual é utilizada pelos membros da família a fim de atender suas necessidades. Sob esse contexto, o presente artigo tem como objetivo compreender sobre a produção para autoconsumo, bem como a percepção dos agricultores familiares sobre a temática da segurança alimentar no munícipio de Vitorino/PR. Realizou-se pesquisa qualitativa com aporte de reunião de formação participativa e uso do método de observação participante, ainda, aplicou-se entrevistas semiestruturadas com vinte e dois agricultores familiares do município Os dados apresentados evidenciam a importância da produção para autoconsumo diante da necessidade ao combate da insegurança alimentar e nutricional do país, sobretudo, no âmbito rural o qual tem passado por muitas transformações. A preocupação com o veneno nos alimentos foi muito presente nas narrativas, de modo que o alimento produzido com agrotóxicos ou industrializado é percebido como sinônimo de alimento que produz insegurança de consumo, além de risco para a saúde.
\end{abstract}

Palavras-chave: Autoconsumo; Desenvolvimento rural; Sustentabilidade; Qualidade de vida.

\begin{abstract}
The predominance of Brazilian land occupied by commodity crops presents a production model that threatens the country's food security and sovereignty. Thus, the practice of production for self-consumption emerges as a strategy to guarantee food security for rural families. It is all types of production carried out within the family unit, which is used by family members in order to meet their needs. In this context, this article aims to understand the production for selfconsumption, as well as the perception of family farmers on the issue of food security in the municipality of Vitorino/PR. Qualitative research was conducted with the support of participatory training meetings and the use of the participant observation method, and semi-structured interviews were applied with twenty-two family farmers in the municipality. The data presented show the importance of production for self-consumption in the face of the need to combat food and nutritional insecurity in the country, especially in the rural area, which has undergone many transformations. The concern with poison in food was very present in the narratives, so that food produced with
\end{abstract}


pesticides or industrialized is perceived as synonymous with food that produces insecurity of consumption, besides being a health risk.

Keywords: Self-consumption; Rural development; Sustainability; Quality of Life.

\section{Resumen}

El predominio de las tierras brasileñas ocupadas por cultivos básicos presenta un modelo de producción que amenaza la seguridad y la soberanía alimentaria del país. Así, la práctica de la producción para el autoconsumo surge como estrategia para garantizar la seguridad alimentaria de las familias rurales. Se trata de todo tipo de producción realizada dentro de la unidad familiar, que es utilizada por los miembros de la familia para satisfacer sus necesidades. En este contexto, este artículo tiene como objetivo comprender la producción para el autoconsumo, así como la percepción de los agricultores familiares sobre la cuestión de la seguridad alimentaria en el municipio de Vitorino/PR. La investigación cualitativa se llevó a cabo con el apoyo de la reunión de formación participativa y el uso del método de observación participante, también se aplicaron entrevistas semi-estructuradas con veintidós agricultores familiares del municipio Los datos presentados muestran la importancia de la producción para el autoconsumo ante la necesidad de combatir la inseguridad alimentaria y nutricional en el país, especialmente en el área rural que ha sufrido muchas transformaciones. La preocupación con el veneno en los alimentos estuvo muy presente en las narrativas, de manera que los alimentos producidos con pesticidas o industrializados son percibidos como sinónimo de alimentos que producen inseguridad de consumo, además de ser un riesgo para la salud.

Palabras clave: Autoconsumo; Desarrollo rural; Sostenibilidad; Calidad de vida.

\section{Introdução}

Os discursos a acerca da necessidade de um planeta sustentável, além de modos produtivos adequados às questões ambientais e sociais, estão visíveis em muitos debates. Todavia, temos presenciado a prevalência de um modelo caótico, pois além de não garantir produtividade ainda incide contra a saúde de agricultores, consumidores e do meio ambiente. O modelo moderno de produção agrícola está baseado na monocultura, na produção em alta escala, na mecanização, bem como no uso intensivo de agroquímicos. Suas consequências conduzem implicações aos aspectos físicos, econômicos e culturais, refletindo na qualidade de vida da sociedade (Nishikawa, 2012; Corrêa et al., 2019).

Gavioli e Costa (2011) comentam que a inovação preconizada pela modernização gerou a incorporação das práticas mecanizadas e agroquímicas na produção, fazendo com que a agricultura se integrasse cada vez mais na indústria. Desse modo, a exploração intensiva dos recursos naturais no contexto hegemônico de fazer agricultura - conhecido empresarialmente como agronegócio - não considera as limitações desses recursos. A equação mais importante nesse âmbito é o resultado de receitas menos custos, ou seja, o aumento de produtividade e das possibilidades de lucro (Marcon, 2012).

No Brasil, por exemplo, na década de 1960 foi marcada por estas inovações, modernizações de equipamentos de trabalho e de insumos sintéticos advindos da Revolução Verde, de igual modo, presumiu-se que a produção para autoconsumo também seria alterada à medida que a modernização da agricultura se consolidasse (Grisa \& Schneider, 2008; Novaes, 2017). A inovação preconizada pela modernização gerou a incorporação de práticas mecanizadas, com a inserção de agroquímicos e engenharia genética, fazendo com que a agricultura se integrasse cada vez mais na indústria.

As dinâmicas ocorridas, a partir do processo descrito acima, mudaram as relações da sociedade moderna, inclusive no que tange a produção e consumo de alimentos. Destaca-se que, conceitualmente, as atividades alimentícias com fins de auto proveniência é entendida como todo tipo de produção realizada dentro da unidade familiar, a qual é utilizada pelos membros da família a fim de atender suas necessidades, dentre essas, se destaca a produção e transformação de alimentos e a produção de bens e ferramentas que são utilizadas no trabalho (Gazolla, 2004).

Nesse contexto, as áreas rurais e a agricultura focalizaram seus esforços no aumento da produtividade e exportação de commodities agrícolas, minimizando a produção dos produtos alimentícios para autoconsumo no interior das propriedades rurais (Dallanôra, 2020). Esse processo colocou em risco a Segurança Alimentar e Nutricional (SAN) de agricultores e de consumidores, pois houve uma quebra da oferta/área colhida de biodiversidade alimentar, destinados, majoritariamente, para população endógena (Dutra \& Souza, 2018). 
A produção para autoconsumo foi concebida em ambientes políticos e institucionais, como um resquício do passado, sendo sinônimo de atraso ou prática avessa à modernização. Foi no início do século XXI diversos pesquisadores brasileiros retomaram estudos sobre essa prática, denotando referência à uma tradição (re)contextualizada, que poderia cumprir vários papéis no âmbito rural contemporâneo (Grisa et al., 2006).

Quanto ao debate sobre SAN no Brasil, esse vem crescendo e tomando espaço na agenda pública desde o ano de 2003. Esse espaço de diálogo e estudo possibilitou vez e espaço ao reconhecimento da produção para autoconsumo como uma estratégia de contribuição para SAN no meio rural (Teixeira, 2007). Nesse sentido, é necessário a definição de SAN, que embora ela já tenha sido associada à apenas à superação da fome ou acerca da segurança sanitária de alimento, a imersão do seu significado vai além, envolve o acesso de todas as pessoas ao alimento em quantidade, diversidade e em qualidade. Ainda, está relacionado com produção, consumo, distribuição, comercialização, estabilidade na oferta de alimentos, políticas públicas, nutrição e saúde, entre outros (Hoyos \& D'agostini, 2017).

Gliessman (2019) ressalta a SAN é um assunto para todos, salientando que falta integração da sociedade para debater e estimular a consciência dessa questão que acaba prejudicando os mais vulneráveis. $\mathrm{O}$ autor ainda complementa que quando o foco é justiça para todas as partes do sistema alimentar, boa comida se torna um negócio de impacto. "O desenvolvimento e o crescimento sustentável do suprimento de frutas, vegetais, nozes e leguminosas, traz os alimentos locais de volta à alimentação diária" (Gliessman, 2019, p.138). Assim, esse trabalho, justifica-se pela importância do tema, principalmente, em conhecer o panorama de agricultores familiares residentes no Município de Vitorino/PR, visto que a região é uma das pioneiras em gado leiteiro, pastagem e soja (IPARDES, 2020), deve-se ter a preocupação com a produção de alimentos diversificados, voltados para as famílias agricultoras, que podem ter alterado seus padrões de consumo no processo de industrialização de seus sistemas.

Diante do contexto exposto, esse artigo tem como objetivo compreender sobre a percepção dos Agricultores Familiares acerca da SAN e entender como esse processo se dá na prática, através das suas atividades produtiva para autoconsumo. Enfatiza-se que esta pesquisa se trada de um estudo de caso no município de Vitorino, Paraná. Espera-se, com essa pesquisa, contribuir com o debate e com formulações de sugestões de políticas públicas acerca da SAN na Agricultura Familiar (AF) direcionados ao Desenvolvimento Rural Sustentável (DRS).

\section{Metodologia}

\subsection{Conhecendo o ambiente de estudo}

A pesquisa ocorreu no município de Vitorino (Figura 1), em que está localizado na Região Sudoeste do Estado do Paraná e possui uma estimativa de 6.879 habitantes. Dessa projeção, cerca de 36,81\% dos residentes está no meio rural. E 40,55\% dessas pessoas que domiciliam no meio rural possuem atividade econômica voltada à agricultura, pecuária, produção florestal, pesca e aquicultura (IBGE, 2020). 
Figura 1. Mapa de Localização do Município de Vitorino.

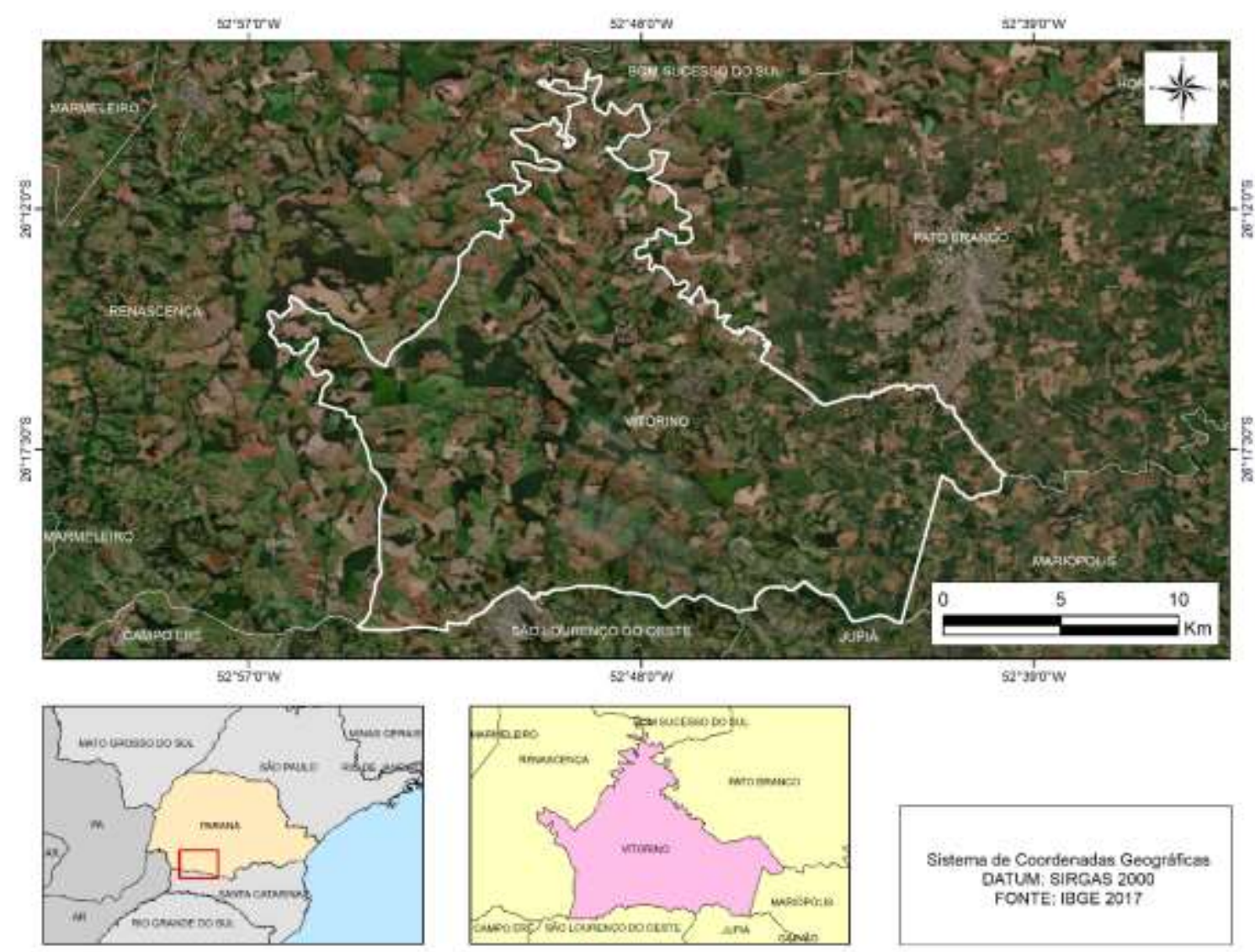

Fonte: Autores (2020).

O município de Vitorino possui ainda aproximadamente 460 estabelecimentos agropecuários pertencentes à $\mathrm{AF}$ e 137 estabelecimentos agropecuários considerados em outras categorias agrícolas, ou seja, a AF possui uma representatividade na região e, consequentemente, no seu desenvolvimento (IBGE, 2020). Esse fator é explicado pela territorialização da microrregião em que o município se encontra, onde teve sua ocupação efetivada, especialmente, por famílias vindas dos estados do Rio Grande do Sul e de Santa Catarina, formando propriedades baseadas na mão de obra familiar (Vottri et al., 2019).

A produção predominante nesses estabelecimentos é a de commodities, dados do ano de 2017 revelam que o município possuía uma colheita de 18.300 hectares (ha) de soja, uma produção de 71.370 toneladas (t) de grãos, feijão 13.000 ha com produção de 14.720 e e 6.000 ha de milho equivalendo a uma produção de 46.000 t. No que tange a pecuária, a produção de galináceos possui maior representatividade, são 105.223 aves criadas no ano de 2017, seguido por rebanho de bovinos, suínos e de vacas para ordenha (IBGE, 2020; IPARDES, 2018). Atualmente a matriz produtiva do município está baseada na produção de grãos e assentada no uso: da mecanização; utilização de sementes melhoradas geneticamente e híbridas; fertilizantes sintéticos; herbicidas, fungicidas, inseticidas e afins (Votri et al., 2019).

\section{Aporte metodológico}

Este trabalho possui um perfil metodológico qualitativo, visto que se dá uma atenção às interpretações por parte dos pesquisadores com suas concepções conceituais sobre o fenômeno em estudo (Pereira et al., 2018). Para compreendermos sobre a produção para autoconsumo e qual percepção dos agricultores familiares sobre segurança alimentar no munícipio de Vitorino/PR, optamos pela abordagem qualitativa, tipicamente usada pelas Ciências Sociais. Nesse contexto, partimos do 
pressuposto que os elementos que constroem a percepção devem ser aferidos e compreendidos a partir de dados que expressem de forma qualitativa a complexidade das relações e como os indivíduos veem e se relacionam com a realidade. A percepção pode ser entendida como aquela ação e efeito de percebermos algo ou alguma coisa através de um de nossos sentidos, coletando assim informações e processando essas em forma de uma ideia sobre o objeto e o seu significado (Brighenti et al., 2015).

A percepção seria nosso contato com o mundo, passando pelos nossos filtros culturais e individuais, resultando nas tomadas de decisões e de consciência (Assis et al., 2020). Assim, essa percepção é uma ação subjetiva, sendo essa, dispensada de experimentos quantitativos para seu entendimento, configurada pela compreensão e interpretação da realidade social e das relações que se estabelecem desse universo e os seus significados (Viganó et al., 2019). Dentre os diversos métodos da pesquisa qualitativa a entrevista semiestruturada aproxima o pesquisador e o entrevistado, deixando esse último a vontade para expressar suas opiniões e percepções. A entrevista semiestruturada, por exemplo, é uma das técnicas que se guia a partir de um roteiro de questões e que permite ao pesquisador realizar mudanças e flexibilizações à medida que as informações vão sendo originadas, enriquecendo a pesquisa com detalhes (Gil, 2008; Ana \& Lemos, 2018). Nesse sentido, foram realizadas entrevistas semiestruturadas com vinte e dois agricultores familiares do município de Vitorino/PR. As perguntas constantes estavam relacionadas aos aspectos sociais, econômicos e ambientais das propriedades, para que assim, pudesse fazer uma relação da percepção de segurança alimentar dos entrevistados com os processos produtivos, especialmente, o para autoconsumo.

As entrevistas foram realizadas com os agricultores familiares no mês de setembro de 2018 e que participavam de palestras propiciadas pela Prefeitura Municipal de Vitorino conjuntamente com docentes do curso de Agronomia da Universidade Tecnológica Federal do Paraná, campus Pato Branco. As palestras foram pensadas a partir das demandas levantadas pelos próprios agricultores, tendo as temáticas: a. Bem estar animal: sistemas de produção-criação prós e contras no sistema leiteiro; b. Solos de Vitorino, questões sobre conservação e uso do solo no município. Essa construção em conjunto se baseia no papel social da Universidade, através da extensão, visando o atendimento a comunidade, bem como compreendendo em uma prática que interliga as trocas de conhecimentos, aliando nesse momento o ensino e a pesquisa.

Dessa forma, para as análises das respostas foram seguidos e estruturados os seguintes passos: (a) o entendimento da dinâmica das propriedades rurais; (b) o contexto do discurso, analisando os sentidos e significados das respostas dos agricultores; e, (c) a interpretação das percepções pelos pesquisadores e a articulação com outros estudos e pesquisas. Essa metodologia foi pensada para que se pudesse ter o mínimo de indicadores qualitativos e compreensão sobre a realidade vivida pela população rural do município. Para melhor visualização, tem-se o traçado metodológico percorrido para atender aos objetivos resumidos no Quadro 1.

Quadro 1. Passos com o resumo metodológico.

\begin{tabular}{|l|l|}
\hline 1. Abordagem & \multicolumn{1}{|c|}{ Qualitativa-descritiva } \\
\hline 2. Objetivos & $\begin{array}{l}\text { Compreender sobre a percepção dos Agricultores Familiares acerca da SAN e entender } \\
\text { como esse processo se dá na prática, através das suas atividades produtiva para } \\
\text { autoconsumo. }\end{array}$ \\
\hline 3. Instrumentos de Coleta & $\begin{array}{l}\text { Reunião de formação participativa; } \\
\text { Observação participante; } \\
\text { Entrevista Semiestruturada. }\end{array}$ \\
\hline 4. Variáveis & $\begin{array}{l}\text { Dinâmica produtiva dos agroecossistemas; } \\
\text { O contexto do discurso, analisando os sentidos e significados das respostas dos agricultores; } \\
\text { A interpretação das percepções pelos pesquisadores e a articulação com outros estudos e } \\
\text { pesquisas; } \\
\text { E a análise relacional holística das variáveis qualitativas obtidas }\end{array}$ \\
\hline
\end{tabular}

Fonte: Autores (2021). 


\section{Resultados e Discussão}

Segurança alimentar e a questão do autoconsumo na agricultura familiar de Vitorino/PR

Antes de aprofundarmos o debate sobre a percepção da SAN e sua importância, é essencial conhecer o perfil produtivo dos agricultores entrevistados, visando uma compreensão holística do cenário. Diante disso, buscamos conhecer os principais cultivos comerciais dos entrevistados. Assim, foram citados cinco sistemas de cultivos: milho (Zea mays), soja (Glycine max), feijão (Phaseolus vulgaris), hortaliças, trigo (Triticum). Dos entrevistados, 17 afirmaram que produzem hortaliças variadas em seus agroecossistemas, e destes, apenas 03 consideram como sistema de cultivo principal da propriedade. A Tabela 1, representa a produção para autoconsumo nos estabelecimentos, sendo os produtos mais citados; repolho, tomate, alface, beterraba, brócolis e plantas usadas para temperos. Todavia, a maioria dos agricultores relatam que essa produção possui uma área pequena.

Tabela 1. Alimentos produzidos para autoconsumo nos estabelecimentos rurais de Vitorino.

\begin{tabular}{l|c}
\hline \multicolumn{1}{c|}{ Produtos } & $\mathbf{N}^{\mathbf{0}}$ de Estabelecimentos \\
\hline Hortaliças & 17 \\
Mandioca & 11 \\
Frutas & 7 \\
Leite & 7 \\
Feijão & 4 \\
Ovos & 3 \\
Batata Doce & 1 \\
Batata Salsa & 1 \\
Batata Inglesa & 1 \\
Mel & 1 \\
\hline
\end{tabular}

Fonte: Autores (2021).

É de extremamente importante salientar que a produção e consumo de hortaliças pode ser um meio gerador de SAN (Vieira et al., 2019). Para Lopes et al. (2017, p.764) as escolhas, ou não, destes alimentos são influenciados por determinantes sociodemográficos, biológicos, culturais, econômicos e ambientais. Percebeu-se que no caso dos agricultores de Vitorino, participantes da pesquisa, essa prática é ativamente realizada, demonstrando que, embora eles produzam cultivos de grãos e lavoura em seus estabelecimentos rurais, ainda se empenham em manter a produção para autoconsumo.

No entanto, a análise a partir do histórico e foco, a produção e consumo de hortaliças poderia ser potencializada com a produção de frutíferas, para que haja uma maior biodiversificação nutricional das famílias agricultoras. A produção de biodiversidade no município foi sucumbida pela ótica do "desenvolvimento" que as commodities ${ }^{1}$ fornecem, visto que os grãos e o pasto são as atividades que possuem a prioridade nesses ambientes.

Em um estudo, realizado no município em questão, os autores descrevem que a Agroecologia fornece uma alternativa à atual estratégia de produção vigente. Para a busca do DRS, visto que a homogeneização de produção agrícola embasada nas culturas temporárias de grãos, principalmente soja, trigo e milho, bem como o emprego ascendente de agroquímicos que gera contaminação das águas e solos, demonstra-se inviável a longo prazo (Votri et al., 2019).

Em relação aos alimentos mais comuns entre os estabelecimentos são as hortaliças folhosas, tuberosas, especialmente, a mandioca (Manihot esculenta) e leguminosas, bem como algumas frutas, de maneira mais tímida. No entanto, a batata doce (Ipomoea batatas), batata salsa (Arracacia xanthorrhiza), batata inglesa (Solanum tuberosum) e mel são produzidos por apenas

\footnotetext{
${ }^{1}$ Em economia, comódite é um termo que corresponde a produtos básicos globais não industrializados, ou seja, matérias-primas que não se diferem independente de quem as produziu ou de sua origem, sendo seu preço uniformemente determinado pela oferta e procura internacional
} 
um único agricultor, que faz comercialização em feiras. Percebeu-se que existe uma troca de produtos entre os estes atores sociais da AF, comum entre os vizinhos e familiares próximos. Conforme depoimento: "o feijão eu ganho do tio" (E14).

Segundo Grisa e Schneider (2008), a produção para o autoconsumo alimenta sociabilidades, firmando relações socais e estabelece compromissos. Também ajuda no intercâmbio da biodiversidade funcional, melhorando a imunidade dos agentes da AF. Para Santosa e Suyanto (2017), a agricultura "mista", ou seja, pautada em diversidade alimentar, pode fornecer benefícios práticos e econômicos para fortalecer a sustentabilidade da cadeia alimentar da AF e também, para o desenvolvimento endógeno de um território.

Ainda, existem agricultores que produzem estes alimentos para autoconsumo com enfoque na agroindustrialização e beneficiamento, como por exemplo, o pão, que é o alimento mais produzido pelos agricultores ( 08 famílias); o queijo em 07 propriedades; 05 propriedades produzem geleias; e apenas uma propriedade faz bolacha.

Apesar de se tratar de agricultores estabelecido na Região Sul e com grande predominância de descendentes italianos (Seyferth, 2013), a produção para autoconsumo de produtos típicos como o salame e vinho já não são mais produzidos. Podemos aferir a hipótese que existe a perda da identidade cultural dessas famílias, em que os hábitos alimentares e culturais não estão sendo continuados, ao contrário estão mudando. Corroborando trazemos o depoimento: "compro na cidade, é tão baratinho, dá muito serviço produzir tudo" (E5).

Tais mudanças de hábitos podem ser observadas através das lentes da industrialização e dos processos globais disseminação de tecnificação de cadeias de produção alimentares, modificando o padrão de consumo e modificando a perda de identidade alimentar (Lopes et al., 2020). E é nesse sentido, também, que há um peso de essencialidade- reconhecido pela Política Nacional de Agricultura Familiar- sobre a produção agrícola local e o seu estímulo ao desenvolvimento sustentável garantindo, assim, condições plenas de SAN (Costa et al., 2021).

Acrescentando a essa possível perda da identidade cultural em relação aos alimentos, também teremos que a produção para autoconsumo é vista como algo trabalhoso e demanda mais horas de trabalho na jornada da propriedade. Assim, teremos que os produtos industrializados ou aqueles oferecidos na cidade são percebidos com qualidade igual e a um preço considerado barato e justo. Grisa e Schneider (2008, p.488) corroboram ao afirmar que "o tempo de trabalho, a mão de obra disponível e os recursos produtivos são reorganizados em função dos cultivos comerciais e estes disputam espaço com o autoconsumo, condicionando-o a uma função de complementariedade". Segundo Camargo e Navas (2017), além da questão da segurança alimentar a produção para autoconsumo é responsável por uma maior autonomia das famílias, já que ficam menos dependentes do mercado e as flutuações de preços.

Para que haja segurança alimentar para a população é preciso que alimentos estejam disponíveis permanentemente, para que o consumo destes resulte em uma vida saudável e ativa. Hoffmann (1995) aponta que para obter esse alimento devese levar em consideração o elemento renda, essencialmente, o poder aquisitivo de cada a alimentação está vinculada ao acesso a produtos de boa qualidade, os quais devem existir suficientemente no mercado, mas, sobretudo, possui relação com as condições econômicas que possibilitam a aquisição dos mesmos. A carência alimentar é apontada como uma das consequências oriundas da pobreza, sendo ela muitas vezes, a causadora da desnutrição em muitos brasileiros. Decorre da baixa ingestão de calorias e nutrientes essenciais para suprir as necessidades do corpo humano.

No entanto, essa análise é limitada, visto que, muitas pessoas ainda que tenham acesso a alimentação sofrem de problemas de obesidade e outras doenças por questões de hábitos e preferencias inadequadas. No caso dos agricultores entrevistados, percebe-se que eles optaram, em sua maioria, pela troca alimentar, deixando de produzir a maior parte do que consomem (com diversidade nutricional e de forma ecológica). Percebe-se que a presença dos monocultivos de grãos, relatados pela maioria, comprometem o autoconsumo, tendo em vista que financeiramente é mais fácil comprar na cidade. 
Os novos Objetivos de Desenvolvimento Sustentável (ODS) veem refletir as mudanças sociais e econômicas a nível mundial, esses, apontam que é necessário a criação de sistemas alimentares sustentáveis e que sejam sensíveis a nutrição, ou seja, a possibilidade de integrar a agricultura com a nutrição (Fao, 2017). Assim:

Um sistema alimentar sensível à nutrição é definido como aquele que reconhece o papel da agricultura e da alimentação na nutrição e coloca a redução da desnutrição dentro de seus objetivos ao buscar o aumento da disponibilidade de alimentos, não apenas em termos de volume, mas também de acessibilidade, diversidade, sustentabilidade e características nutricionais (Fao, 2017, Pg.18).

Ao refletirmos sobre as diversas falas em relação à SAN, questão dos industrializados e do uso dos agrotóxicos, podemos perceber uma falta de consciência ou de conhecimento sobre os termos ou práticas adotadas pelas famílias. Para Silva e Garavello (2012), com a perspectiva da ideia do desenvolvimento e da industrialização o estilo de vida da população sofreu mudanças, acabando por descaracterizar as disposições socioculturais em relação a dietas mais saudáveis. Em relação a produção de alimentos oriundos da criação de animais, a criação de galinhas para autoconsumo está presente na maioria dos estabelecimentos onde 09 agricultores a possuem, esse dado é justificado partindo do pressuposto quanto à facilidade na criação desse animal, visto que é muito comum a criação de galinhas soltas no pátio. Ainda, 08 agricultores possuem criação de suínos; 06 têm para autoconsumo bovinos; 03 caprinos ou ovinos e apenas 01 agricultor possui peixe.

Um dos principais motivos para que as famílias continuem com essa produção trata-se da insegurança proveniente da qualidade, sanidade e manejo de carnes comercializadas no mercado (Grisa \& Schneider, 2008). Essa visão é confirmada na fala de um agricultor ao denotar que a carne apta para consumo é aquela que não possui antibiótico (E4). A grande insegurança e medo que é retratada pelos agricultores quanto ao consumo de alimentos que contenham medicamentos, agrotóxicos ou sinais de contaminação, está associada a toda representação de risco que é posta ao consumidor, devido suas experimentações com alimentos indesejáveis, bem como sua reflexividade quanto ao que entendem por um alimento de qualidade e que seja remetido à saúde, bem-estar e prazer.

Ao questionarmos os agricultores sobre o que entendem por SAN, a maioria dos depoimentos apontam a qualidade como o principal elemento, fazendo associação ao consumo de alimentos livre de agrotóxicos e/ou alimentos naturais. O que acaba sendo contraditório, diante às práticas produtivas que os mesmos executam. Dos entrevistados, 10 agricultores apontaram o agrotóxico como um elemento que não deve estar presente na alimentação, como se observa nos depoimentos da Tabela 2:

Tabela 2. depoimento de agricultores sobre a percepção de segurança alimentar - agrotóxico.

\begin{tabular}{|c|c|}
\hline Agricultor Entrevistado & Depoimento \\
\hline E1 & $\begin{array}{c}\text { "Acho que para ter segurança tem que cuida o que passa na produção para aquela } \\
\text { cultura e respeitar a carência". }\end{array}$ \\
\hline E3 & $\begin{array}{c}\text { "Nós temos que protege nossos alimentos dos venenos, não se tem mais qualidade, } \\
\text { tudo contaminado". }\end{array}$ \\
\hline E5 & "comer um produto sadio sem agrotóxico". \\
\hline E7 & "Produzir o que vai comer, o que não tem agrotóxico". \\
\hline E11 & "sem agrotóxico". \\
\hline E12 & "comer o que é mais saudável, livre de químicos e antibióticos". \\
\hline E14 & "alimentação equilibrada e saudável, sem veneno, orgânica". \\
\hline E16 & "Ingerir alimentos com selo de qualidade e os que colhem sem defensivo químico". \\
\hline $\mathrm{E} 21$ & "comida saudável e livre de agrotóxico". \\
\hline $\mathrm{E} 22$ & "Livre de agrotóxico, natural". \\
\hline
\end{tabular}

Fonte: Autores (2021). 
Grisa (2009, p.19) realizou uma pesquisa em quatro municípios do Rio Grande do Sul, para buscar entender a percepção de atores da AF sobre a SAN. A autora revela que os agricultores aos produzirem alimentos possuem preferência por produtos livres de agrotóxicos, "garantindo qualidade e sanidade, ou quando imprescindível, procura-se usar o mínimo necessário e respeitar as normas de segurança". Esse elemento pode ser visualizado na fala de um dos agricultores: "Limpeza e higiene da comida e da horta, ter comida boa e de qualidade, e usar água boa para irrigar" (E2).

Outro ponto de destaque na percepção dos agricultores se refere quanto a qualidade dos alimentos como sinônimo de segurança alimentar. Podemos visualizar em diversas falas, tais como: "Alimentação sadia e de boa qualidade" (E15), "qualidade do alimento, produzir e consumir. Não sou fã de coisas compradas" (E19), "qualidade do que comer" (E20).

O entrevistado E19, afirma em seu discurso não ser "fâ" de fazer compras no supermercado, supondo que produtos industrializados não possuem qualidade equivalente aos que produz em sua unidade. Essa concepção vai de encontro a afirmação de Grisa (2007), em que a dependência ao mercado diminuiu ao ponto que o agricultor passa a produzir seus próprios alimentos, dessa forma, as famílias rurais dispõem de maior autonomia sobre a dimensão alimentar além de estabilidade e segurança. Conforme já apontado por Gazolla e Schneider (2007) a produção para autoconsumo muitas vezes é interpretada como a geradora da segurança alimentar, onde alimentos produzidos dentro da unidade familiar são considerados mais "limpos" ou com qualidade nutritiva "superior" aos adquiridos na cidade.

No entanto, é importante compreender outros elementos que contemplam a preferência do entrevistado aos produtos produzidos em sua unidade familiar. Sendo o trabalho do agricultor, sua relação com a terra e a construção de sua identidade social, fundamentos para a produção de auto proveniência, não apenas como um alimento produzido, mas pelas relações sociais que são produzidas e reproduzidas a seus descendentes (Gazolla \& Schneider, 2007). Para tanto, ao questionar a qualidade dos alimentos industrializados, a valorização de alimentos tradicionalmente produzidos no próprio estabelecimento rural é acentuada e vem criando aproximações entre produção-consumo (Cruz \& Schneider, 2010).

Ainda, de acordo com as falas a variedade de alimentos é apontada como elemento importante na dieta da família, bem como ela compor a alimentação como garantia de segurança alimentar. Trazemos algumas falas para exemplificar: "tem que te um arroz, feijão, carne e verdura" (E10); "Comer arroz e feijão com um queijinho, comer frutas e vegetais" (E17); "Comer um pouco de tudo" (E18). Quando questionados quanto ao entendimento sobre uma alimentação saudável, no geral os agricultores percebem e responderam que seria uma alimentação que envolve o consumo de alimentos naturais, sem agrotóxicos e produtos industrializados, além de pouca ingestão de gordura. Devendo ainda, manter uma dieta balanceada em frutas, legumes, verduras e também, como presente na fala: "almoço com feijão, arroz e salada" (E14).

Existem depoimentos associados estritamente a não ingestão de alimentos com agrotóxicos, "saudável seria comida natural, livre de agrotóxico" (E22), como também falas relacionadas aos alimentos industrializados "Quanto menos industrializado" (E8); e associação desses dois elementos "sem defensivos e sem ser industrializado" (E16). Essas falas denotam que o "veneno", além de se apresentar na figura de agroquímicos é também apontado na percepção dos agricultores para referenciar alimentos industrializados.

Entretanto, podemos verificar naquelas falas que fazem alusão ao uso do agrotóxico como sendo não saudável, teremos uma percepção contrária ao que se refere a produção para comercialização. Em sua grande maioria, os entrevistados afirmam que produzir sem agrotóxicos não é possível e seu uso é justificado pelo efeito imediato e pela facilidade de eliminar pragas nas lavouras, não havendo prejuízos a saúde quando aplicados nessas situações. Essa constatação é apontada por Grisa (2009), ao afirmar que a preferência dos agricultores está no cuidado da produtividade comercial, prevalecendo o uso de agrotóxicos, fertilizantes químicos, inseticidas e herbicidas visando maior rendimento monetário, tornando evidente a diferença de manejo quanto a produção para autoconsumo da produção comercial. 
Desse modo, cabe aqui destacar ao que Beck (2011) se refere a uma sociedade de risco, na qual a consequência dos processos de industrialização e modernização passou a ser questionado pela sociedade, acarretando em um ambiente de insegurança e medo no que se consome. Essa insegurança na alimentação é denotada nas falas dos agricultores ao revelarem que uma alimentação saudável é o que se produz no interior da unidade familiar (E20), sobretudo não devendo conter hormônio nas carnes e nem agroquímicos nas hortaliças (E19).

De igual modo, tal insegurança é percebida em relação aos alimentos industrializados, sugerindo a ideia do impuro e do artificial, ou ainda, referido aquele alimento não mais operado por mão de obra familiar e em condições de ritos e laços afetivos. O produto industrializado nesse sentido é visto como algo feito em obscura cozinha e que pode ser perigosa para a saúde (Santos, 2008). Essa percepção também é replicada no que tange a uma alimentação fora do domicílio, por exemplo com o E10: "lá uma vez na semana, um churrasco, comer fora só tem porcaria". Sua fala é carregada de insegurança pelo alimento produzido fora da propriedade/domicílio, semelhante ao depoimento de E2 e E5 ao afirmarem que são suas esposas que preparam o alimento para toda família consumir, trazendo um sentimento: de segurança, conhecimento de procedência, hábitos de higiene, práticas de preparo e conservação.

Ademais, outro depoimento afirma que para obter uma alimentação saudável é preciso "comer um pouco de tudo, não se ater somente aos naturais" (E6), a fala desse entrevistado expressa sua percepção de que para uma alimentação saudável é preciso consumir diversos tipos de alimentos e não se aplica de modo exclusivo a ingestão de alimentos naturais, sendo também o industrializado considerado saudável. Visão que é compartilhada em outro entrevistado: "Tudo que é alimento é saudável, tem gente que não sabe comer, tem que comer de tudo" (E9). Assim, podemos afirmar que ambos entrevistados partilham da mesma ideia, em que segundo eles comer de tudo (naturais e industrializados) é sinônimo de uma alimentação saudável.

Nesse cenário, de como os agricultores compreendem e percebem o que seria segurança alimentar perguntamos quais produtos ou práticas de autoconsumo que eles realizam em suas propriedades, já que essa apresenta como uma alternativa estratégica na garantia da segurança alimentar no rural. Autoconsumo é conceituado por Grisa et al. (2010) como uma prática tradicional de produção realizada no interior da unidade familiar, bem como pelos seus membros cujo objetivo é o próprio consumo. Leite (2004) acrescenta que o autoconsumo pode ser ampliado para a alimentação de animais e para o suprimento de diversas atividades agrícolas, também realizadas no interior do estabelecimento rural.

Segundo Grisa e Schneider (2008), a produção para o autoconsumo é um fator relevante para a segurança alimentar, pois permite o acesso facilitado a diversos alimentos que são capazes de oferecer nutrientes de que o organismo depende. Ainda segundo os autores, trata-se de uma prática:

[...] que respeita as preferências alimentares das comunidades locais, suas práticas de preparo e consumo, e serve como um instrumento de preservação da cultura, dada que muitas destas práticas são passadas de pais para filhos, em consonância com as condições socioambientais e a própria história local (Grisa \& Schneider, 2008, p.489).

Não podemos deixar de explanar estudos atuais que debatem o tema, como os de Costa et al. (2021) que abordam um debate sobre Insegurança alimentar em agricultores, atestado que este fator é uma violação do direito humano à alimentação adequada. Nesse sentido, a implementação de programas com potencialidade de reduzir problemas oriundos da modernização na agricultura a qual vem refletindo na alimentação de toda a população. Conforme aponta Anjos et al. (2004), essa modernização é responsável pelo desprestígio da produção própria, bem como a perda de raízes culturais.

Ademais, as políticas públicas para a agricultura familiar não estão conseguindo estimular o retorno da produção para autoconsumo nas propriedades. Já que grande parte das ações e projetos visam a produção para o mercado, afastando cada vez mais estratégias que assegurem a segurança alimentar. Nesse sentido, nos cabe a reflexão de que é de suma importância que 
sejam repensadas as políticas públicas para a agricultura familiar numa perspectiva da segurança alimentar do núcleo familiar, bem como o retorno à produção para autoconsumo. Retomando as conclusões do presente trabalho, notamos que existem certas contradições e até mesmo falta de informações sobre o amplo conceito de segurança alimentar.

Reflexões: Considerando possibilidades para novos rumos, olhares baseados em Boaventura de Sousa Santos

As reflexões do sociólogo Boaventura de Sousa Santos (2005, p.24) contribuem ao reconhecer que "vivemos em uma época em que a ideia de que não há alternativas ao capitalismo conseguiu um nível de aceitação que provavelmente não tem precedentes na história do capitalismo mundial". Além do mais, o autor propõe ações de resistência, afim de esquivar-se desse modelo hegemônico, usa o termo "cosmopolitismo" para descrever práticas e discursos de resistência contra hegemônicos.

Experiências de resistência e alternativas ao modelo hegemônico estão sendo construídas em diversos espaços. Santos (2005) apresenta nove teses de alternativas de produção, na qual trazemos ao debate quatro delas. A primeira tese refere-se a ideia de que as alternativas de produção devem ser consideradas além do enfoque econômico, pois "o seu potencial emancipatório e as suas perspectivas de eixo dependem, em boa medida, da integração que consigam entre processos de transformação econômica e processos culturais, sociais e políticos" (Santos, 2005, p. 64). Sob o ponto de vista agrícola é necessária uma avaliação global para melhor visualização dos impactos produzidos pela intensa exploração de recursos, evitando que essa se torne uma prática usual. Os pressupostos hegemônicos possuem resistência às críticas, justificam os meios usados na produção em vista dos benefícios obtidos associados ao interesse econômico. Dessa forma, devemos nos conduzir a uma reflexão sobre a real necessidade imediatista na produção de inovações de plantio e também na fabricação de insumos químicos para os ambientes rurais (Marcon, 2012).

A segunda tese refere-se às alternativas de produção inseridas em redes de colaboração e de suporte mútuo. "Um dos fatos mais importante para o aparecimento, sobrevivência e expansão das alternativas de produção é a existência de um movimento social mais amplo que produza e mantenha a sua integridade" (Santos, 2005, p. 65). A AF por sua vez, nos leva a crer que a partir de uma relação dialética se apresenta como um ponto de resistência, não apenas perceptível no modelo produtivo, mas na forma de atuação em suas propriedades de uma maneira geral, bem como na proliferação de novas identidades sociais que desencadeiam a criação de grupos. Suas relações no campo, bem como cooperativismo e engajamento estão em processo de transformação. Assim, o estabelecimento de redes funciona para sustentar a contra hegemonia de produção, objetivando ambientes mais sustentáveis, saudáveis e seguros (Nishikawa, 2012).

A terceira tese trata da democracia participativa e uma democracia econômica. Em que as suas características são de uma produção não capitalista com potencial de substituir a relação típica de patronato, por uma democracia participativa no cerne das unidades de produção (Santos, 2005). Para a produção capitalista o objetivo sempre será a lucratividade, já na produção alternativa, levam-se em consideração outros elementos, como a participação e a sustentabilidade. Sendo possível a abertura de janelas para criação de espaços democráticos de decisão sobre o que produzir, como comercializar e também consumir (Marcon, 2012). Por fim, a quarta tese de Santos (2005) refere-se as formas alternativas de conhecimento como caminhos diferenciados de produção. "Na procura de alternativas de produção capitalista, o contributo de culturas minoritárias ou híbridas, marginalizadas pela hegemonia do capitalismo, e o da ciência moderna é fundamental" (Santos, 2005, p. 67).

Marcon (2012) afirma que para estabelecer um modo de produção contra hegemônico, é necessário investimento em pesquisas e também na produção de tecnologias alternativas, bem como, no direcionamento de uma nova perspectiva de ideias para os agricultores familiares, através da extensão rural, contribuindo para fortalecimento de meios mais ecológicos e saudáveis. É nessa lógica que, para os atores sociais colaboradores dessa pesquisa, expõe-se propostas de retomada e reconexão, bem como com a quebra hegemônica, para assegurar qualidade de vida, sustentabilidade e saúde. 


\section{Considerações Finais}

Os dados apresentados nesse estudo visam contribuir com a temática da importância da produção para autoconsumo e da necessidade do combate a insegurança alimentar e nutricional do país, sobretudo, no âmbito rural. A preocupação com o veneno nos alimentos foi muito presente nas narrativas, de modo que o alimento produzido com agrotóxicos ou industrializado é percebido como sinônimo de alimento que traz certa insegurança de consumo, além de risco para a saúde. No entanto, o uso dessas sustâncias em lavouras é muito usual, sendo essa prática reconhecida como um "mal necessário" a fim de garantir melhor produção e consequentemente maiores retornos financeiros.

Do mesmo modo, é preciso que o agricultor visualize essa importante prática de produção para o autoconsumo a fim de garantir alimentação a todos da família em quantidade suficiente, com variedade e sobre tudo com qualidade, mantendo raízes culturais que deverão ser passadas de geração a geração. Ponderamos a necessidade de maiores informações à população dos malefícios do uso de agroquímicos e dos debates sobre SAN. Nesse sentido, a agricultura familiar e a produção de alimentos (para o mercado e autoconsumo) dialogam com ações e políticas que garantam a manutenção da autonomia desses agricultores, na incorporação de sistemas combinados e com bases agroecológicas de produção, para fortalecer a segurança alimentar e o desenvolvimento sustentável.

Boaventura de Sousa Santos contribui no debate contra hegemônico da produção de alimentos que atinge as diversas maneiras de SAN e na qualidade de vida das famílias agricultoras, possibilitando propostas de retomada e reconexão, bem como com a quebra hegemônica, para assegurar qualidade de vida, sustentabilidade, saúde/bem-estar e não perder formas tradicionais para autoconsumo alimentar, que agregam uma riqueza sociocultural.

Frisa-se que é necessária uma explanação maior em estudos parecidos, nas mais diversas regiões e que esse fator resulte em orientação e políticas públicas para como estratégia aumentar a renda dos agricultores e de elevar a oferta de alimentos para autoconsumo, reverberando também na qualidade de vida.

\section{Agradecimentos}

Os autores agradecem à Universidade Tecnológica Federal do Paraná (UTFPR) - Campus Bato Branco, bem como aos agricultores familiares que se dispuseram a essa pesquisa, ao Programa de Pós-graduação em Desenvolvimento Regional (PPGDR) e à Coordenação de Aperfeiçoamento de Pessoal de Nível Superior (CAPES).

\section{Referências}

Anjos, F. S., Caldas, N. V., Grisa, C., Niederle, P. A., \& Schneider, E. P. (2004). Abrindo a caixa-verde: estudo sobre a importância econômica do autoconsumo na agricultura familiar meridional. II Seminário internacional sobre Desenvolvimento Regional, 1-19.

Ana, W. P. S., \& Lemos, G. C. (2018). Metodologia Científica: a pesquisa qualitativa nas visões de Lüdke e André. Revista Eletrônica Científica Ensino Interdisciplinar, 4(12), 531-541.

Assis, D. M. S. D., Tavares-Martins, A. C. C., Beltrão, N. E. S., \& Sarmento, P. S. D. M. (2020). Percepção ambiental em comunidades tradicionais: um estudo na Reserva Extrativista Marinha de Soure, Pará, Brasil. Ambiente \& Sociedade, 23.

Beck, U. (2011). Sociedade de Risco: Rumo a uma outra modernidade. trad. Sebastião Nascimento. Editora, 34.

Brighenti, J., Biavatti, V. T., \& de Souza, T. R. (2015). Metodologias de ensino-aprendizagem: uma abordagem sob a percepção dos alunos. Revista Gestão Universitária na América Latina-GUAL, 281-304.

Camargo, J. S. M., \& Navas, R. (2017). Programas Institucionais de Compra da Agricultura Familiar no Município de Ribeirão Grande/SP: Uma Análise a Partir da Produção e Consumo. Revista Nera, (35), 230-245.

Costa, L. A. D., Marques, A. D. A., Sampaio, J. R. F., Santana, W. J. D., \& Rocha, E. M. B. (2021). Food insecurity in farmers: violation of the human right to adequate food. Cadernos Saúde Coletiva, 29, 122-132.

Corrêa, M. L. M., Pignati, W. A., \& Pignatti, M. G. (2019). Segurança Alimentar, produção de alimentos e saúde: um olhar para os territórios agrícolas de Mato Grosso. ACENO-Revista de Antropologia do Centro-Oeste, 6(11), 129-a. 
Cruz, F. T. D., \& Schneider, S. (2010). Qualidade dos alimentos, escalas de produção e valorização de produtos tradicionais. Revista Brasileira de Agroecologia, 5(2), 22-38.

Dallanôra, I. B. (2020) Modernização do espaço rural brasileiro: "novo” olhar para a agricultura familiar. Caderno de Geografia, 30(2), $289-289$.

Dutra, R. M. S.; De Souza, M. M. O. (2017) Cerrado, Revolução Verde e a Evolução no Consumo de Agrotóxicos. Sociedade \& Natureza, 29(3), 469-484.

Gavioli, F. R., \& Costa, M. B. B. (2011). As múltiplas funções da agricultura familiar: um estudo no assentamento Monte Alegre, região de Araraquara (SP). Revista de Economia e Sociologia Rural, 49(2), 449-472.

Gazolla, M. (2004). Agricultura familiar, segurança alimentar e políticas públicas: Uma análise a partir da produção para autoconsumo no território do Alto Uruguai/RS. (Dissertação de Mestrado. Programa de Pós-Graduação em Desenvolvimento Rural/UFRGS.) Porto Alegre - RS, 287p.

Gazolla, M., \& Schneider, S. (2007). A produção da autonomia: os "papeis" do autoconsumo na reprodução social dos agricultores familiares. Estudos: sociedade e agricultura. 15(1), 89-122.

Gil, A. C. (2008). Métodos e técnicas de pesquisa social. (6a ed.), Ediitora Atlas SA.

Gliessman, S. (2020). A vision for future food and agriculture systems. Journal Agroecology and Sustainable Food Systems. 44, 137-138.

Grisa, C. (2009). Riscos e consumo de alimentos na agricultura familiar: a reemergência da produção para autoconsumo. Encontro Nacional de Estudos do Consumo, $1-25$

Grisa, C., \& Schneider, S. (2008). "Plantar pro gasto": a importância do autoconsumo entre famílias de agricultores do Rio Grande do Sul. Revista de Economia e Sociologia Rural, 46(2), 481-515.

Grisa, C., Schneider, S., Conterato, M. A., \& Ferreira, F. (2006). A produção para autoconsumo no Brasil: uma análise a partir do Censo Agropecuário 2006. Aspectos multidimensionais da agricultura brasileira: diferentes visões do Censo Agropecuário, 165-186.

Grisa, C., Gazolla, M., \& Schneider, S. (2010). A" produção invisível" na agricultura familiar: autoconsumo, segurança alimentar e políticas públicas de desenvolvimento rural. Agroalimentaria, 16(31), 65-79.

Hoffmann, R. (1995). Pobreza, insegurança alimentar e desnutrição no Brasil. Estudos avançados, 9(24), 159-172.

Hoyos, C. J. C., \& D'Agostini, A. (2017). Segurança alimentar e soberania alimentar: convergências e divergências/Food Security and Food Sovereignty: convergences and divergences. Revista Nera, (35), 174-198.

IBGE. Instituto Brasileiro de Geografia. Cidades-Vitorino. https://www.ibge.gov.br/cidades-e-estados/pr/vitorino.html

IPARDES. Instituto Paranaense de Desenvolvimento Econômico e Social (2018). Caderno Estatístico Município de Vitorino, 2018. http://www.ipardes.gov.br/cadernos/MontaCadPdf1.php?Municipio=85520

IPARDES. Instituto Paranaense de Desenvolvimento Econômico e Social (2020). Caderno Estatístico Município de Vitorino, 2020. http://www.ipardes.gov.br/cadernos/MontaCadPdf1.php?Municipio=85520

Leite, S. (2004). Autoconsumo y sustentabilidad en la agricultura familiar: una aproximación a la experiencia brasileña. Políticas de seguridad alimentaria y nutrición en América Latina, São Paulo: Hucitec, 123-181.

Lopes, A. C. S., Menezes, M. C. D., \& Araújo, M. L. D. (2017). O ambiente alimentar e o acesso a frutas e hortaliças:"Uma metrópole em perspectiva” 1. Saúde e Sociedade, 26, 764-773.

Lopes, A. C. S., Menezes, M. C. D., \& Araújo, M. L. D. (2017). O ambiente alimentar e o acesso a frutas e hortaliças:“Uma metrópole em perspectiva” 1. Saúde e Sociedade, 26, 764-773.

Marcon, T. (2012). Progresso, modernização e sustentabilidade: desafios para as políticas agrícolas. Olhar de Professor, 15(1), 131-142.

Nishikawa, D. L. L. (2012). Alternativas ao modelo hegemônico da agricultura: o caso da associação de produtores rurais dos Garcias no município de Bom Repouso $(M G)$. Tese de doutorado. Universidade Estadual Paulista, Faculdade de Ciências e Letras de Araraquara.

Novaes, H. T. (2017). Reestruturação do campo e o fetichismo da "revolução verde". Revista Ciências do Trabalho, (9).

Organização das Nações Unidas para a Alimentação e a Agricultura (FAO). (2017). Panorama da segurança alimentar e nutricional, Santiago.

Santos, B. D. S. (2002). Produzir para viver: os caminhos da produção não capitalista. Rio de janeiro: Civilização brasileira, 3.

Santos, L. A. S. (2008). O corpo, o comer e a comida: um estudo sobre as práticas corporais alimentares cotidianas a partir da cidade de Salvador. SciELOEDUFBA.

Santosa, I., \& Suyanto, A. (2017). The Benefit of Mix Farming Agribusiness to Strengthen Food Sustainability of The Farmer Household at Agrotourism Areas. Journal of Art and Humanities, 6(10), 24-31.

Seyferth, G. (2013). Memória coletiva, identidade e colonização: representações da diferença cultural no Sul do Brasil. MÉTIS: história \& cultura, 11(22).

Pereira A. S. et al. (2018). Metodologia da pesquisa científica.

Teixeira, I. B. C. (2007). O desafio da segurança alimentar e nutricional (SAN) para as famílias rurais: O que temos no nordeste? III Jornada Internacional de Políticas Públicas, 1-8. 
Research, Society and Development, v. 10, n. 13, e461101321499, 2021

(CC BY 4.0) | ISSN 2525-3409 | DOI: http://dx.doi.org/10.33448/rsd-v10i13.21499

Viganó, C., Gonçalves, L. M., Cattani, J. P. C., \& Campos, J. R. D. R. (2019). Autoconsumo e agroecologia: um retrato da agricultura familiar no município de Vitorino-PR. X Seminário Internacional sobre Desenvolvimento Regional.

Vieira, E. D. L. P., Mendonça, X. M. F. D., \& do Carmo Almeida, J. F. (2019). Produção e consumo de hortaliças orgânicas: eixo gerador de segurança alimentar. Revista de Extensão da Integração Amazônica, 1(2), 88-91.

Vottri, M., Godoy, C. M. T., Godoy, W. I., \& da Rocha Campos, J. R. (2019). A Agroecologia como alternativa ao modelo de produção vigente: Algumas reflexões para o município de Vitorino/PR. Sociedade em Debate, 25(3), 171-185. 